\title{
Proksimal tibia medial açık kama osteotomisi: Spacer plak ile tespit
}

\section{Proximal tibia medial opening wedge osteotomy: fixation plates with spacer}

\author{
Mehmet Aşık, Gökhan Polat, Taha Kızılkurt \\ İstanbul Üniversitesi İstanbul Tıp Fakültesi, Ortopedi ve Travmatoloji Anabilim Dalı, İstanbul
}

Yüksek tibial osteotominin (YTO) genç ve aktif hastalarda hem erken dönemde mekanik aksı laterale taşıyarak medial eklem dekompresyonu ile ağrıyı azalttığı hem de uzun dönemde artroza ilerlemeyi yavaşlattığı bilinmektedir. Son zamanlarda bu tekniğin endikasyonları sadece varus dizilimi veya erken evre artroz ile sınırlı kalmayıp aynı zamanda kronik posterolateral instabiliteler ve bağ rekonstrüksiyonlarına destek amaçlı kullanılmaktadır. Proksimal tibia medial açık kama osteotomisi (PTMAKO) günümüzde lateral kapalı kama osteotomisine göre avantajları sebebiyle daha çok tercih edilmektedir. Bununla birlikte kemik grefti gerektirmesi, posterior tibial eğimin iyatrojenik olarak artabilmesi, aşırı düzeltmede patellofemoral basınçların artması ya da kaynamama gibi olası dezavantajları mevcuttur. PTMAKO'dan sonra kaynamama olasılığını ve düzeltme kaybını en aza indirmek için yeterli stabil fiksasyon zorunludur. PTMAKO'yu daha stabil hale getirmek amacıyla çeşitli implantlar üretilmiştir. Spacer (kamalı) plaklar ve kilitli plaklar en çok kullanılan fiksasyon yöntemleridir. PTMAKO cerrahisinin başarısındaki en önemli unsur uygun hasta seçimi ve uygun cerrahi tekniktir. Bu sebeple cerrahi öncesi planlama ve implant seçimi titizlikle yapılmalıdır.

Anahtar sözcülkler: yüksek tibial osteotomi; spacer plak; açık kama
High tibial osteotomy (HTO) reduces pain by medial joint decompression by moving the mechanical axis laterally in the early period and slows the progression to arthrosis in young and active patients. Recently, the indications of this technique are not only limited to varus malalignment or early stage arthrosis, but also for chronic posterolateral instabilities and to support ligament reconstructions. Proximal tibia medial open wedge osteotomy (PTMOWO) is preferred HTO technique today because of its advantages over lateral closed wedge osteotomy. However, there are potential disadvantages of this technique such as requiring bone grafting, iatrogenic increase of posterior tibial slope, increased patellofemoral pressures in overcorrection and nonunion. Stable fixation is necessary to minimize risk of nonunion and correction loss after PTMOWO. Various implants have been produced to make it more stable. Spacer plates and locking plates are the most used fixation methods. The most important factor in the success of PTMOWO surgery is appropriate patient selection and appropriate surgical technique. For this reason, preoperative planning and implant selection should be done with care.

Key words: high tibial osteotomy; spacer plate; open wedge
D izdeki varus dizilimi dengesiz kuvvet dağılımına sebep olarak medial kompartmanda yük artışına sebep olmaktadır. Bu durum kıkırdak, menisküs ve ligamanlarda orantısız strese sebep olmakta ve medial eklem artrozuna zemin hazırlamaktadır. ${ }^{[1]}$ Semptomatik dizilim bozukluğunda fizik tedavi, kama tabanlıklar ve medial yükten kesici dizlikler gibi konservatif tedavi yöntemleri, hem medial ekleme binen yükü azaltmak hem de artroza ilerlemeyi yavaşlatmak için kullanılsa da genç ve aktif hastalarda beklentileri karşılamamaktadır. ${ }^{[2]}$ Yüksek tibial osteotominin (YTO) genç ve aktif hastalarda hem erken dönemde mekanik aksı laterale taşıyarak medial eklem dekompresyonu ile ağrıyı azalttığı hem de uzun dönemde artrozda ilerlemeyi yavaşlattığı bilinmektedir. Son zamanlarda bu tekniğin endikasyonları sadece varus dizilimi veya erken evre artroz ile sınırlı kalmayıp aynı zamanda kronik posterolateral instabiliteler ve ligaman rekonstrüksiyonlarına destek amaçlı kullanılmaktadır. ${ }^{[3]}$ Proksimal tibia medial açık kama ostetomisinin (PTMAKO) bir diğer özelliği koronal planda düzeltme yaptığı gibi sagittal planda da düzeltme yaparak diz stabilitesine katkı verebilecek değişikliklerin de yapılmasına izin vermesidir. ${ }^{[3]}$

- İletişim adresi: Op. Dr. Taha Kızılkurt, İstanbul Üniversitesi İstanbul Tıp Fakültesi Ortopedi ve Travmatoloji Anabilim Dalı, İstanbul Tel: 0506 - 5026187 e-posta: drtahakizilkurt@gmail.com

- Geliș tarihi: 20 Ocak $2020 \quad$ Kabul tarihi: 3 Mart 2020 

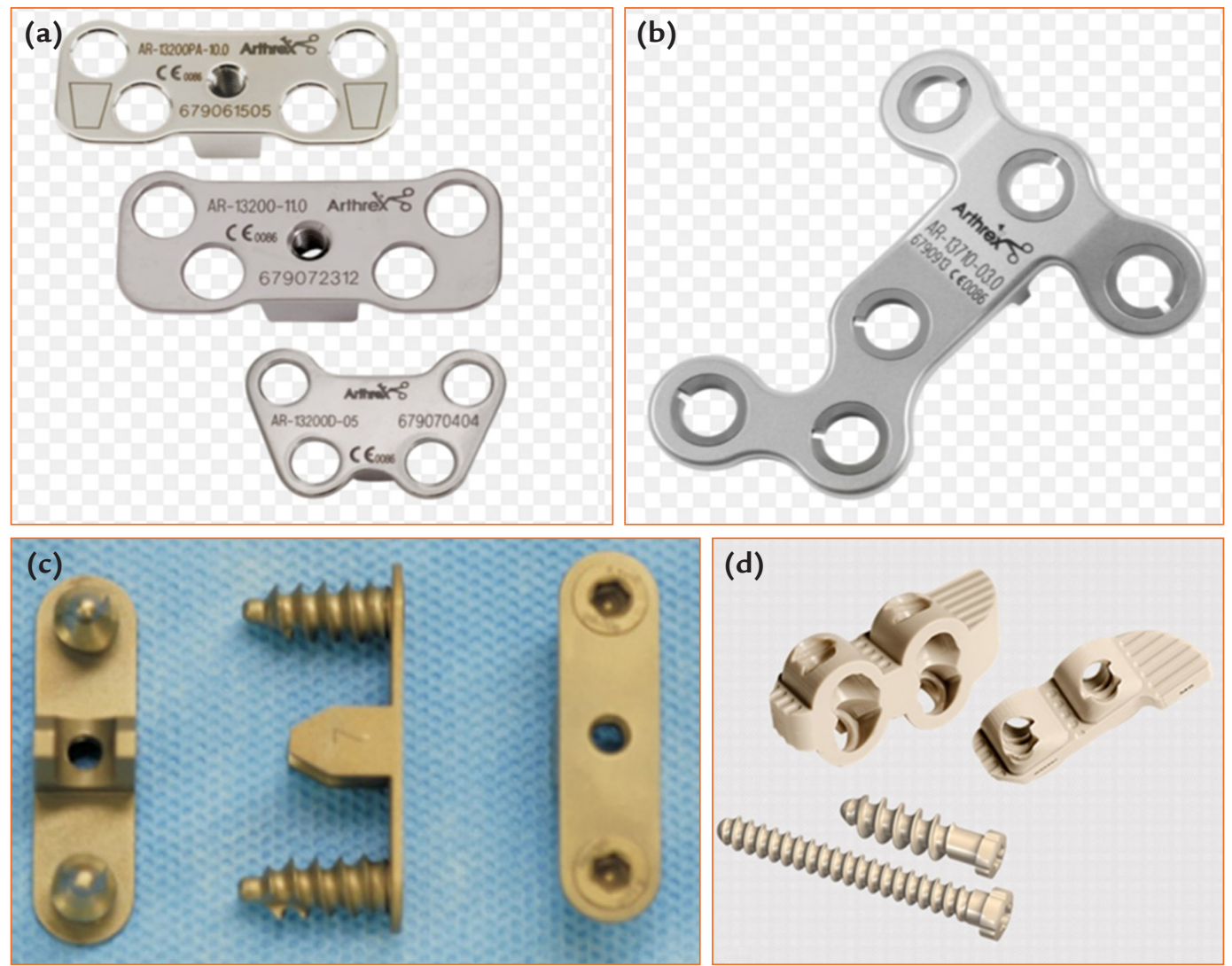

Şekil 1. a-d. Puddu plağı (a). CountourLock ${ }^{\mathrm{TM}}$ HTO Plağı (b). Aescula plağı (c). iBalance implant (d).

PTMAKO günümüzde lateral kapalı kama osteotomisine göre fibula osteotomisi gerektirmemesi, peroneal sinir hasarı riskinin düşük olması, ekstremitede kısalmaya sebep olmaması, tek bir kesi ile uygulanması, kasların içinden geçmemesi, kemik kaybı olmaması, düzeltme miktarının daha kolay ayarlanabilmesi ve total diz protezine geçişin görece daha kolay olması sebebiyle daha çok tercih edilmektedir. Bununla birlikte kemik grefti gerektirmesi, posterior tibial eğimin iyatrojenik olarak artabilmesi, aşırı düzeltmede patellofemoral basınçların artması ya da kaynamama (12,5 mm'den fazla düzeltme gerektiren olgular) gibi dezavantajları da bildirilmiştir. ${ }^{[4]}$ PTMAKO'dan sonra kaynamama olasılığını ve düzeltme kaybını en aza indirmek için yeterli stabil fiksasyon zorunludur. ${ }^{[5]}$ PTMAKO'yu daha stabil hale getirmek amacıyla çeşitli implantlar üretilmiştir. Spacer (kamalı) plaklar ve kilitli plaklar en çok kullanılan fiksasyon yöntemleridir.

Puddu kendi adıyla anılan, ileride gelişebilecek kollapsı önlemek için üzerinde osteotomi yüzeylerini içeriden destekleyen ve yükseklikleri 5 ile $17,5 \mathrm{~mm}$ arasında değişen 9 farklı boyda metal bloğu olan (kamaIı) (spacer tooth) plağını (Puddu plağı; Arthrex, Naples
FL, USA) geliştirmiştir. ${ }^{[6,7]}$ Staubli ve DeSimoni tarafindan geliştirilen ve daha sonra Lobenhoffer ve ark. tarafından popülarize edilen, TomoFix plağı da günümüzde yaygın olarak kullanılmaktadır. ${ }^{[8,9]}$ Kilitli plak teknolojisinin gelişimine paralel olarak, Puddu plakları da güncellenmiş ve kilitli vida delikleri içeren son hali kullanıma sunulmuştur. Günümüzde kama desteği olan Puddu plağı, Artrex firması tarafindan proksimal ve distal vida sayısı arttırılarak tekrar dizayn edilmiştir ve ContourLock ${ }^{\mathrm{TM}}$ HTO plağı olarak kullanıma sunulmuştur (Şekil 1). Aescula plağı (B. Braun Korea, Seoul, Korea), iBalance system (Arthrex), Antony-K (Clamart-France), Esenkaya ve ark. (Hipokrat, Turkey, TR2002 02021Y), metal bloklu kilitli plak (OhtoFix Ohtomedical Co. Ltd., Goyang, Korea) gibi kamalı plaklar da PTMAKO'da kullanılmaktadır. ${ }^{[10-12]}$

\section{CERRAHI PLANLAMA}

Hasta seçimi ve uygun cerrahi teknik tedavi başarısında en önemli etkenlerdir. Bu sebeple hastanın tüm hikayesi dikkatle alınmalı, varsa eski cerrahi girişimleri 
değerlendirilmeli ve radyolojik açıdan detaylı olarak incelenmelidir. Diz eklemi hareket açıklığı, bağ stabilitesi ve alt ekstremite dizilimi değerlendirilmelidir. Her üç kompartman, özellikle ağrı yönünden dikkatle incelenmelidir. Lateral kompartmanda patolojiyi işaret eden semptomlar varsa ona yönelik manyetik rezonans görüntüleme (MR) ile lateral kompartman değerlendirilmelidir. Olası instabiliteye sebep olacak travma varlığında instabiliteyi değerlendirmek için stress grafileri ve MR dikkatle incelenmelidir. Kronik posterolateral köşe yaralanmaları için varus stres testi, ters pivot shift testi, dial testi ve eksternal rotasyon rekürvatum testleri yapılmalı ve not edilmelidir. Değerlendirme sonucunda ön ya da arka çapraz bağa ait yetmezliğin tespit edildiği durumlar PTMAKO için kontrendikasyon oluşturmamaktadır. Hastanın mevcut durumuna göre sagittal planda posterior tibial slobun arttırılması, azaltılması veya genç orta yaşlı hastalarda eş zamanlı bağ rekonstrüksiyonları uygulanabilir. ${ }^{[13]}$

Diz çevresi osteotomilerinde amaç ekstremitenin mekanik aksını (eksenini) yükün bindiği patolojik taraftan sağlam tarafa taşımaktır. Bu nedenle standart diz grafileri; ayakta çekilmiş ön-arka grafi, diz eklemi $30^{\circ}$ fleksiyonda lateral grafi, Rosenberg grafisi, $45^{\circ}$ fleksiyonda çekilecek patella merchant grafi ile eklemin genel değerlendirilmesi yapılmalıdır. Alt ekstremitenin dizilim bozukluğunun ayrıntılı olarak değerlendirilmesi ve deformite analizi için ise patellanın santralize olduğu ekstremite uzunluk grafileri (ortoröntgenografi) çekilmelidir. Dizilimin değerlendirmesine; ilk olarak mekanik aks ölçümü ile başlanır. Femur başı merkezinden ayak bileği ekleminin merkezine çekilen çizgi (frontal planda alt ekstremitenin mekanik ekseni) normalde diz eklemi merkezinin ortalama $8 \pm 7 \mathrm{~mm}$ medialinden geçmelidir. Ardından proksimal medial tibial açı, lateral femoral distal açı ve JLCA (joint line congruency angle) ölçümü gerçekleştirilerek deformite analizi tamamlanır. Yapılan bu deformite analizinin ardından hedeflenen proksimal tibia düzeltme açısı belirlenir ve şablon üzerinde oluşacak açık kamanın genişliği tespit edilir. Bu düzeltme açısı tibia platosunun medial sınırından itibaren \%62'ye denk gelen nokta (Fujisawa noktası) hedef alınarak, biri femur başı merkezinden biri ayak bileği merkezinden çizilen iki doğru arasındaki açı ölçülerek belirlenir. ${ }^{[14,15]}$ Lateral korteks kırığından korunmak amaciyla osteotomiyi lateral korteksten $1 \mathrm{~cm}$ uzak olarak planlamak gerekmektedir.

PTMAKO öncesi sagittal düzlemde tibia slobunu değerlendirmek çok önemlidir. Bu değerlendirmeye göre operasyon içinde plak yerine göre slobu ayarlamak (azaltmak-arttırmak) mümkün olabilmektedir. $\mathrm{Bu}$ amaçla, lateral grafide tibia şaftıyla tibial plato arasındaki açı ölçülmeli ve not edilmelidir. ${ }^{16]}$
PTMAKO kontrendikasyonları; $20^{\circ}$ 'den fazla düzeltme gerekliliği, lateral kompartman artrozu veya menisektomi öyküsü ya da gerekliliği, romatoid artrit, açık büyüme plakları, eklem hareket kısıtlılığı $\left(90^{\circ}\right.$ 'den az fleksiyon $10^{\circ}$ 'den fazla fleksiyon kontraktürü), patellofemoral ağrı veya patella baja (osteotomi patella kıkırdağına binen yükü arttırmaktadır) olarak sayılabilir. ${ }^{[17]}$ Aynı zamanda sigara içicilerinde de kaynamama riski sebebiyle daha dikkatli yaklaşılmalıdır. ${ }^{[18]}$

\section{CERRAHI TEKNIK}

Hastalar "supin" pozisyonda radyolusen ameliyat masasında hazırlanır. Cerrahi tedaviye, eklemin artroskopik değerlendirilmesi ile başlanabilir. Bu şekilde patellofemoral ve lateral kompartmanın değerlendirilmesi dışında, eşlik eden intraartiküler lezyonların tedavisi yapılabilir.

Proksimal tibia anteromedialinde medial kollateral ligamanın hemen önünden yapılan yaklaşık 7-8 cm'lik longitudinal insizyon ile cilt-cilt altı geçilir. Fasyanın $\mathrm{L}$ şeklinde açılması sonrasında, medial kollateral ligamanın yüzeyel kısmı kemikten posteriora doğru sıyrılır (Şekil 2). Osteotomi kılavuzu yerleştirilerek eklem hattının yaklaşık 1-2 cm distalinden ilk kılavuz tel ekleme paralel olarak gönderilir (Şekil 3). Ardından ikinci kılavuz tel, fibula proksimalini hedefleyecek şekilde uygun açıda lateral kortekse doğru gönderilir. Skopi kontrolünde, Kirschner telinin (K-teli) rehberliğinde medial korteksin ilk 2-3 cm'lik kısmı kesici motor ile kesilir, sonrasında 10, 25 ve 35 mm'lik ince osteotomlar ile lateral korteksin kırılmamasına dikkat edilerek anterior ve posterior korteks kesileri ile osteotomi tamamlanır. Eğer lateral korteks kırıldıysa lateral korteksin staple ile desteklenmesi stabilite için önem arz etmektedir. Kirschner telleri çıkarılarak, osteotomi hattına kama şeklindeki genişletici (spreader) uygulanarak osteotomi hattı distrakte edilir (Şekil 4).

Ameliyat öncesi yapılan planlamaya uygun distraksiyon miktarı elde edilmesi sonrasında, alt ekstremite mekanik aksı kablo testi ile değerlendirilir. Uygun düzeltme sağlandığında distraktör çıkarılarak, osteotomi kaması osteotomi hattına uygulanır (Şekil 5). Üzerinden uygun kamalı Puddu plağı osteotomi hattına yerleştirilir. Osteotomi hattı, proksimale 2 adet 6,5 $\mathrm{mm}$ boyutunda spongioz, distale ise 2 adet $4,5 \mathrm{~mm}$ 'lik kortikal vida uygulanan Puddu plağı ile, skopi kontrolünde, tespit edilir (Şekil 6).

Plak anterioru ve posteriorundaki defekt sahası; sağlanan düzeltme miktarı ve hastaya ait faktörler göz önünde bulundurularak iliak kanattan alınan kama şeklindeki otogreftler ile ya da allogreftler ile doldurulur. 

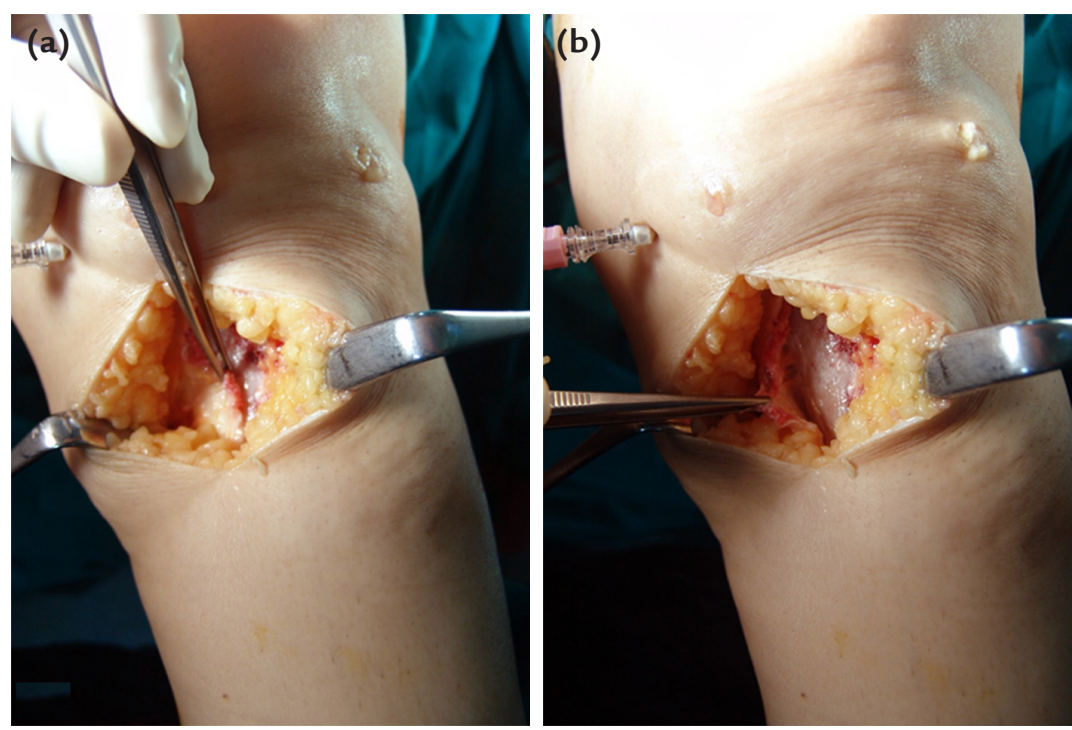

Şekil 2. a, b. Proksimal tibia anteromedialinde medial kollateral ligamanın hemen önünden yapılan insizyon (a). Fasyanın L şeklinde açılması (b).
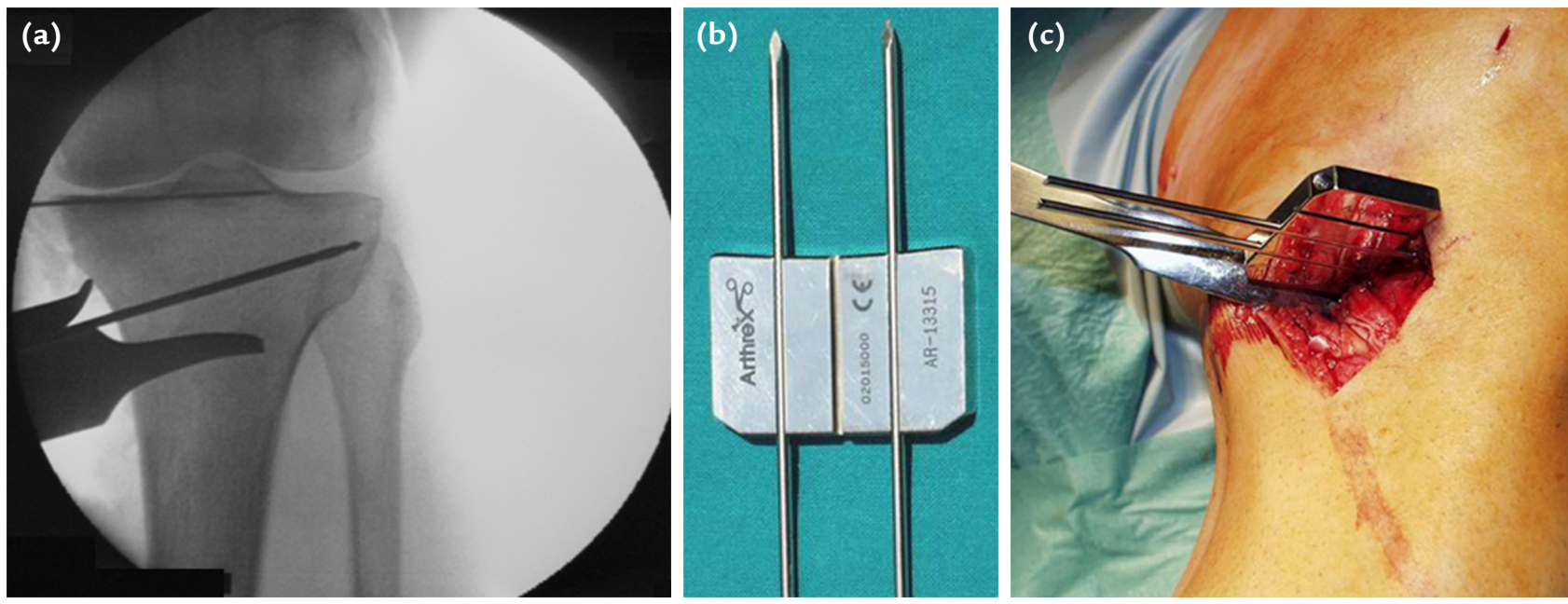

Şekil 3. a-c. Tibia metafizinden fibula proksimaline doğru uzanacak K-telinin kılavuz üzerinden gönderilmesi (a). Kılavuz görünümü (b). Kılavuz üzerinden gönderilen 2. tel sonrası klinik görünüm (c).
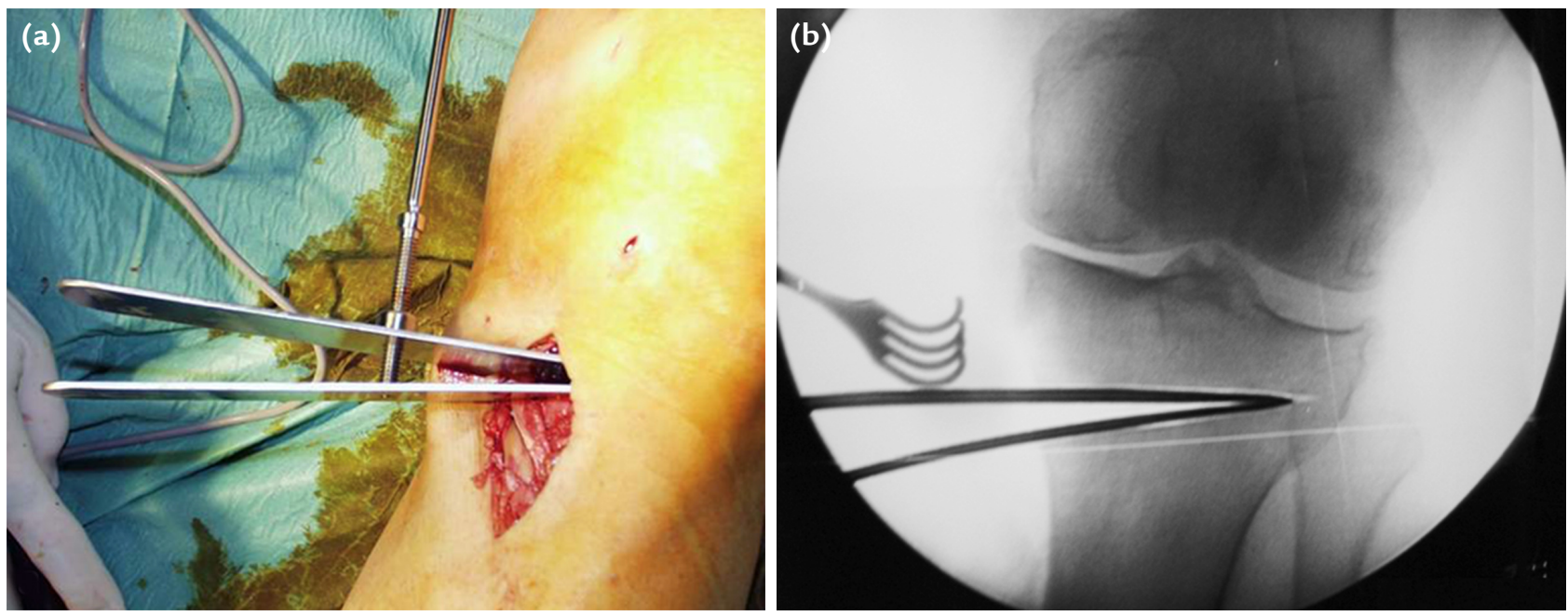

Şekil 4. a, b. Lateral korteksin kırılmamasına dikkat edilerek osteotominin uygulanması sonrasında osteotomi hattının hedeflenen açıda distraksiyonunu gösteren klinik fotoğraf (a) ve skopi görünümü (b). 

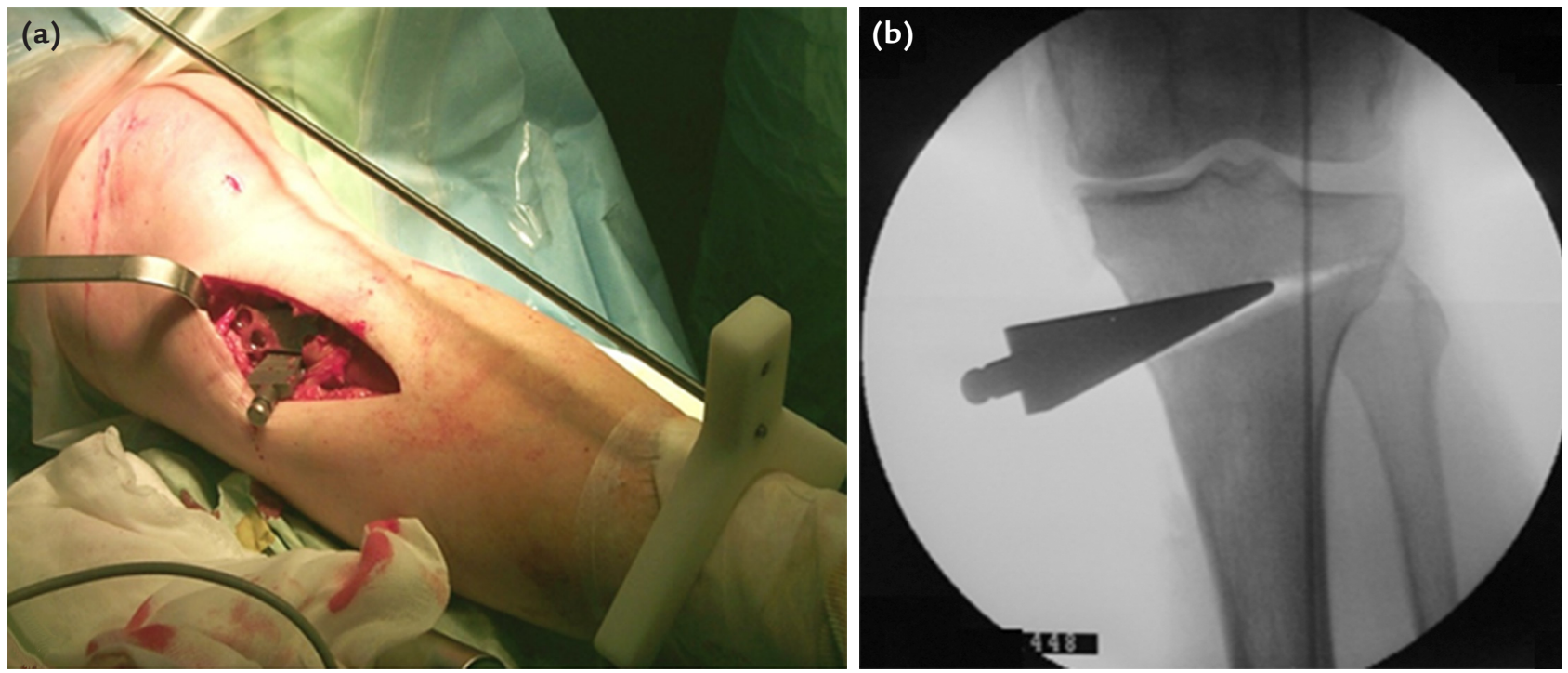

Şekil 5. a-c. Ameliyat öncesi yapılan planlamaya uygun distraksiyon miktarı elde edilmesi sonrasında, alt ekstremite mekanik aksı kablo testi ya da dizilim aparatı ile değerlendirilir (a). Uygun düzeltme sağlanması sonrasında osteotomi hattına kama denemesi uygulanır (b). Kama üzerinden uygun kamalı Puddu plağı osteotomi hattına yerleştirilir (c).
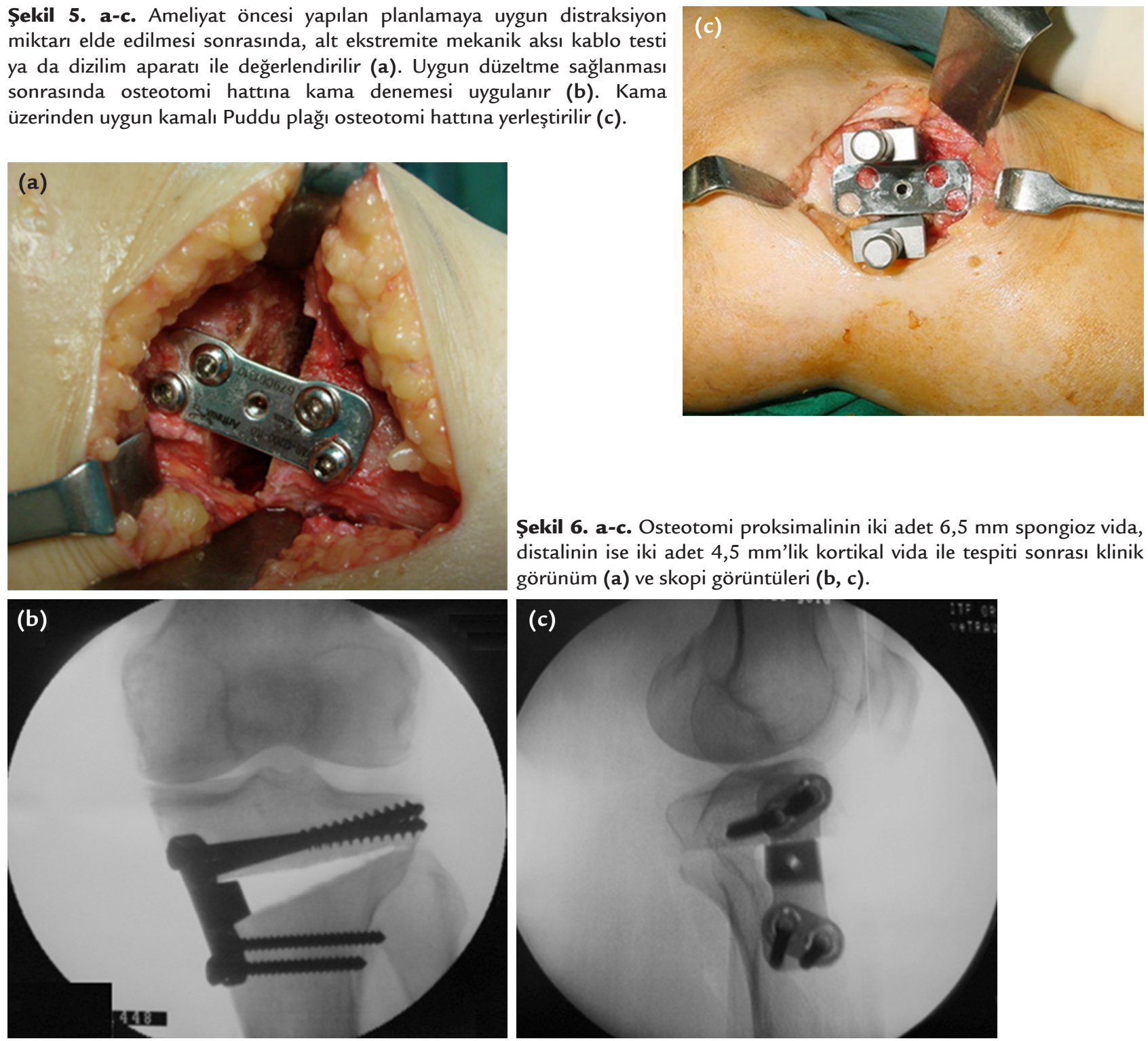

Şekil 6. a-c. Osteotomi proksimalinin iki adet $6,5 \mathrm{~mm}$ spongioz vida, distalinin ise iki adet 4,5 mm'lik kortikal vida ile tespiti sonrası klinik görünüm (a) ve skopi görüntüleri $(b, c)$.

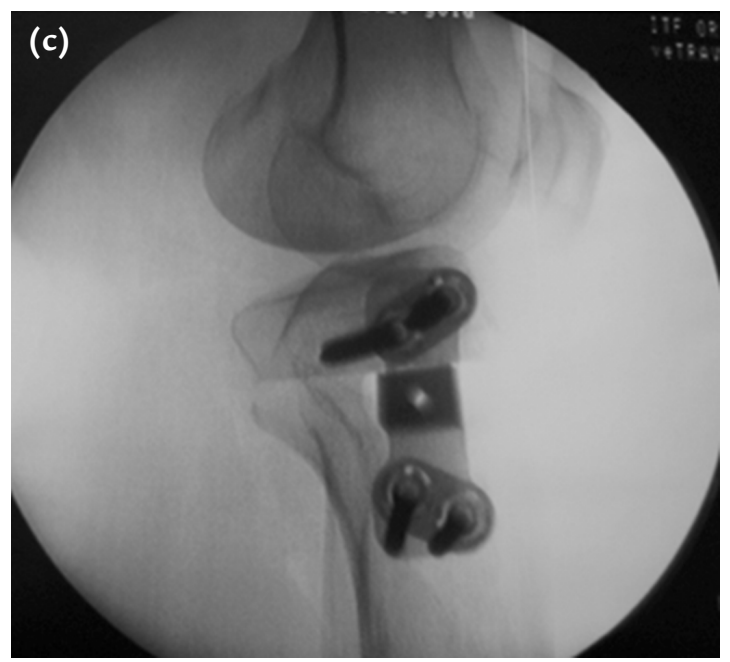




\section{Ameliyat Sonrası Rehabilitasyon}

Ameliyat sonrası erken dönemde CPM (continuous passive motion) ile eklem hareketi ve kuadriseps güçlendirme egzersizlerine başlanmalıdır. Erken dönemde mobilizasyon esnasında dizden menteşeli breys cerrahın tercihine göre (ameliyat sırasında lateral korteksin kırılıp kırılmaması, hastanın kemik kalitesi, tespitin stabilitesi gibi faktörler göz önüne alınarak) kullanılabilir. Bununla birlikte hastalar yaklaşık altı hafta boyunca çift koltuk değneği ve parsiyel yükle yürütülmelidir. Kaynama sonrasında tam yüke geçilerek, kademeli olarak koltuk değnekleri bıraktırılır.

\section{TARTIŞMA}

PTMAKO medial kompartman aşırı yüklenmesi olan varus dizlerinde, erken evre medial kompartman artrozlarında ve de kronik diz instabilitelerinde etkili bir tedavi yöntemidir. ${ }^{[3]}$ PTMAKO özellikle son zamanlarda sadece varus dizilimi veya medial kompartman artrozuyla sınırlı kalmayıp; posterolateral köşe yaralanmaları gibi kronik instabiliteler, başarısız olmuş bağ rekonstrüksiyonları sonrasında revizyon ameliyatlarında dizilim düzeltme gibi ameliyatlarda da kullanılmaya başlanmıştır. ${ }^{[19,20]}$

Medial kompartman artrozu tedavisinde birçok tedavi seçeneği tarif edilmiş olmasına rağmen, PTMAKO halen genç-orta yaşlı hasta grubunda eklemi koruyan en etkili tedavi yöntemidir. Temel prensip; alt ekstremite mekanik aksının dejenere olmuş olan medial kompartmandan, daha sağlıklı kıkırdağa sahip olan lateral kompartmana kaydırmaktır. ${ }^{[21]}$ Coventry tarafından uzun dönem sonuçlarının yayınlanması sonrasında popülaritesi artan YTO, tarihsel süreç içerisinde temel prensibi değişmemekle birlikte teknik, kullanılan tespit materyalleri ve rehabilitasyon protokolleri açısından birçok modifikasyona uğramıştır. Puddu'nun 2000'li yılların başından itibaren diz çevresinde kendi ismiyle anılan plağı ile uyguladığı açık kama osteotomiler, medial açık kama osteotomisinin başarısını arttırmış ve popülarite kazanmasını sağlamıştır. ${ }^{[7,22,23]}$

PTMAKO'nun diğer bir avantajı hem koronal hem de sagittal planda düzeltme yapabilir olması ve bu sayede özellikli vakalarda diz stabilitesine katkı sağlayabilmesidir. ${ }^{[24]}$ Tibial slop ayarlaması osteotomi planlaması ile ya da plak ve kama pozisyonlaması ile ayarlanabilmektedir. Tibial slobu arttırmak için kama anteriora, azaltmak için posteriora konulmaIıdır. ${ }^{[17]}$ Instabilite tedavisinde PTMAKO tek olarak, rekonstrüksiyonla beraber veya aşamalı cerrahilerle uygulanabilmektedir. Cantin ve ark. yapmış oldukları sistemik derlemede rekonstrüksiyon ile beraber PTMAKO uygulamasının daha iyi sonuç verdiğini belirtmişlerdir. Rekonstrüksiyonla beraber yapılan olguların, rekonstrüksiyon yapılmamış olgulara göre daha iyi ameliyat sonrası (postoperatif) akitivite skorları olduğunu belirtmişlerdir. ${ }^{[25]}$ Arthur ve ark. 3. derece posterolateral köşe yaralanması ve de varus dizilimi olan 21 hastalık prospektif çalışmalarında \%38 hastada YTO sonrasında ligaman rekonstrüksiyonu ihtiyacının duyulmadığını belirtmişlerdir. ${ }^{[3]}$

Spacer plaklar (Puddu, Aescula vb.) daha ince profilli ve daha küçük olmaları sebebiyle daha küçük insizyon ve daha az yumuşak doku hasarı ile uygulanabilmektedir. Bunun yanında daha ince ve küçük olmaları sebebiyle yeterli rijit fiksasyon zorluğu ve buna bağlı gecikmiş kaynama, kaynamama ve fiksasyon kaybı ve posterior slop artışı gibi durumlarla karşılaşılabilir. ${ }^{[26,27]} \mathrm{Bu}$ komplikasyonlardan kaçınmak amacıyla da yük verme konusunda daha konservatif yaklaşılmalıdır. ${ }^{[28]}$ Kilitli plaklar (Tomofix) daha rijit bir fiksasyonu sağlayarak erken yüke izin vermektedir. Yalnız daha büyük olmaları ve de kalın profilli olmaları yumuşak doku hasarını arttırmaktadır. ${ }^{[29]}$

Martin ve ark. tek merkezde tedavi edilmiş 323 hastaya ait hasta serilerinde medial açık kama osteotomisinde karşılaşılan komplikasyonları sınıflandırmışlardır. ${ }^{[30]}$ Bu sınıflandırmaya göre yazarlar lateral kortekste ayrışmamış (non-deplase) kırılma, gecikmiş yara iyileşmesi, ayrışmamış lateral tibia plato kırığı, hematom ve artmış tibial eğimi $\left(\geq 10^{\circ}\right)$ ek tedavi gerektirmeyen evre 1 komplikasyonlar, gecikmiş kaynama, selülit, sınırlı implant kırılması (tek vida gibi), eklem sertliği, derin ven trombozu ve tip 1 kompleks bölgesel ağrı sendromunu uzamış ameliyatsız tedavi gerektiren komplikasyonlar, aseptik kaynamama, derin enfeksiyon, tip 2 kompleks bölgesel ağrı sendromu, implant yetmezliği ve düzeltme kaybını ise ek cerrahi gerektiren komplikasyonlar olarak tanımlamışlardır. ${ }^{[30]}$ Bu konuda yapılan diğer bir çalışmada, Woodacre ve ark. medial açık kama osteotomisi uygulanan 115 hastada, ortalama komplikasyon oranının \%31 olduğunu bildirilmişlerdir. ${ }^{[31]}$ Bu komplikasyonların \%9,6'sının minör yara enfeksiyonları olduğu, derin enfeksiyonların \%3,5, kaynamama nedeniyle revizyon ihtiyacının $\% 4,3$ olduğu, vasküler yaralanmanın \%1,7, kompartman sendromunun \%0,9 olduğu bildirilmiştir. İrritasyona bağlı olarak implant çıkarılma gerekliliğinin \%7 olarak bildirildiği bu hasta grubunda, Puddu plağı uygulanan hastalardaki komplikasyon oranının Tomofix ve Orthofix uygulanan hastalara benzer olduğu sonucu bildirilmiştir. ${ }^{[31]}$ Osti ve ark. spacer 
plak kullanımı sonrası komplikasyonlara baktıkları çalışmalarında fiksasyon materyallerinden çok yaş, cinsiyet, vücut kitle indeksi, osteotomi kama büyüklügüyle ilgili olduğunu belirtmiş ve $7 \mathrm{~mm}$ 'den daha az düzeltme yapılan olgularda daha az komplikasyon oranı bildirmişlerdir. ${ }^{[32]}$

Medial açık kama osteotomisi sonrasında stabil tespit ve erken hareket, klinik sonuçları doğrudan etkileyen önemli bir faktördür. Bu açıdan literatürde spacer plaklar ile, diğer tespit materyallerini karşılaştıran yayınlar mevcuttur. ${ }^{[33-36]}$ Stoffel ve ark.'nın, Puddu plağını Tomofiks ile karşılaştırdıkları çalışmalarında, lateral korteksi kırılmayan olgularda benzer biyomekanik stabilite bildirilirken, lateral korteksi kırılan olgularda Puddu plağı uygulanan gurubun lateral tarafa da tespit ihtiyacı olduğu bildirilmiştir. Lateral korteksin kırıldığı olgularda Tomofix plağının daha iyi fiksasyon sağladığını belirtmişlerdir. ${ }^{[33]}$ Zhim ve ark., Puddu plağını Hoffman II eksternal fiksatörü ile karşılaştırdıkları çalışmalarında, Puddu plağı ile daha iyi düzeltme sağlanabildiğini tespit etmişlerdir. ${ }^{[34]}$ Agneskirchner ve ark., yaptıkları biyomekanik çalışmada rijit, uzun, sabit açılı kilitli vidaları olan plakların daha stabil olduğunu bildirmişlerdir. ${ }^{[35]}$ Buna rağmen bu plakların kaba ve daha çok yer kaplaması nedeniyle hemen her vakada implant çıkarılma gereksinimi duyulduğu da ifade edilmiştir. ${ }^{[37]}$ Kim ve ark. Aescula, Puddu ve Tomofix plaklarını karşılaştırdığı biyomekanik çalışmalarında aksiyal kompresyon ve siklik yüklenme testlerinde istatistiksel bir farkın olmadığını tespit etmişlerdir ve spacer plaklar ile slop ayarının daha iyi yapılabildiğini belirtmişlerdir. ${ }^{[36]}$

PTMAKO sonrası osteotomi hattını doldurmak ve kaynamayı hızlandırmak amacıyla otogreft, allogreft, sentetik kemik (hidroksiapatit, b-trikalsiyumfosfat vb.) greftleri ile beraber yardımcı olarak trombositten zengin plazma, büyüme faktörleri, kemik iliği aspiratları gibi birçok seçenek mevcuttur. ${ }^{[38]}$

Günümüzde kemik grefti hem osteokondüktif, hem osteoindüktif özellikleri olması sebebiyle altın standart olarak belirtilmektedir. Sentetik kemik greftleri donör saha morbiditesini azaltmasına rağmen kompresyon kuvvetlerine karşı daha zayıftır. ${ }^{[37,38]}$ Ayrıca bizim serimizde sentetik greft uygulanmış vakalarda sentetik greftin osteotomi hattında daha geç kaynama bulgusu gösterdiği görülmüştür. ${ }^{[6]}$ Yeni jenerasyon kilitli, rijit plak-vida uygulaması sonrasında greftleme gerekliliği konusunda yapılan bir çalışmada 14 mm'ye kadar düzeltme gerektiği vakalarda greftleme yapılmayabileceğini bildirilmiştir. ${ }^{[39]}$ Bununla birlikte $10 \mathrm{~mm}$ ve üzerinde düzeltme gereken, aşırı kilolu ya da tütün kullanımı gibi risk faktörleri olan hastalarda otojen greftleme öneren yayınlar da mevcuttur. ${ }^{[37]}$ Puddu plağının, proksimal ve distal vida sayısının birer arttırıldığı ve kilitlenebilir vidaların uygulanabildiği yeni dizayn kamalı plağı olan "ContourLock ${ }^{\mathrm{TM}}$ " YTO plağı ile ilgili sınırlı sayıda biyomekanik çalışma mevcuttur. ${ }^{[0]}$ TomoFix small stature (TomoFix sm), TomoFix standard (TomoFix std) (Synthes, Oberdorf, Switzerland), ContourLock ${ }^{\mathrm{TM}}$, iBalance ve ikinci jenerasyon PEEKPower (Arthrex, Munich, Germany) plakları biyomekanik olarak karşılaştırıldığı bir çalışmada, yazarlar "ContourLock ${ }^{\mathrm{TM}}$ " ve "iBalance" plağının diğer plaklara göre daha stabil olduğunu, proksimali daha geniş T-şeklinde dizayn edilmiş ve farklı yönlerde vida gönderebilen ve daha anteriora ve proksimale konulan plakların mekanik olarak daha stabil olduğunu bildirmişlerdir. ${ }^{[40]}$

\section{İstanbul Tıp Fakültesi Tecrübesi}

1990 ve 2010 yılları arasında YTO uyguladığımız hastaların (187 hastanın 195 dizi) retrospektif değerlendirmesinde, Puddu plağı ile medial açık kama osteotomisi yapılan ve ortalama 11,7 yıllık takipli 88 hastanın son kontrolleri yapılarak son durumları değerlendirildi. Yaş ortalaması 44,6 \pm , 4 olan hastaların cerrahi tedavileri sonrasında üç hastada implant yetmezliği, bir hastada kaynama gecikmesi, bir hastada tespit kaybı ve malunion, bir hastada derin doku enfeksiyonu ve bir hastada derin ven trombozu olmak üzere $\% 8,4$ komplikasyon tespit edildi. Hastaların ortalama 11,7 yıllık takipleri sonrasında son kontrollerinde; ortalama KSS (Knee Society Clinical Rating System) skoru 70,4 $\pm 10,7$ ve ortalama HSS (Hospital for Special Knee Surgery) diz skoru $64,7 \pm 10,2$ olarak bulundu. Takip süresi içinde 12 hastaya $(\% 13,4)$ total diz artroplastisi ile revizyon uygulandığı görüldü. ${ }^{[23]}$

\section{SONUÇ}

PTMAKO varus dizilimine sahip diz medial kompartman osteoartritinde, kronik instabilitelerde başarılı bir tedavi seçeneğidir. Kapalı kama osteotomisinin tersine çift planlı düzeltme sağlayabilmesi, daha az komplikasyon oranlarına sahip olması ve diz protezine dönüşün daha kolay olması sebebiyle günümüzde tercih edilen YTO tekniğidir. PTMAKO'da fiksasyon spacer plak ya da kilitli plaklar ile sağlanabilmektedir. Kilitli plaklarla daha rijit fiksasyon sağlanabilmekte; kamalı plaklarla ise yumuşak dokuya daha saygılı yaklaşım ve de daha kolay tibial slop ayarlaması yapılabilmektedir. Altın standart kabul edilen bir fiksasyon yöntemi yoktur. Tedavide hekimlerin bu avantajları ve dezavantajları iyi değerlendirip ona göre bir tercih yapmaları gereklidir. PTMAKO'da elde edilen klinik başarının implant seçimlerinden ziyade uygun hasta seçimi ve uygun teknik ile sağlandığını görmekteyiz. 


\section{KAYNAKLAR}

1. Brouwer RW, Huizinga MR, Duivenvoorden $T$, van Raaij TM, Verhagen AP, Bierma-Zeinstra SM, et al. Osteotomy for treating knee osteoarthritis. Cochrane Database of Systematic Reviews 2014(12). Crossref

2. Wolfe S, Brueckmann F. Conservative treatment of genu valgus and varum with medial/lateral heel wedges. Indiana medicine: the journal of the Indiana State Medical Association 1991;84(9):614-5.

3. Arthur A, LaPrade RF, Agel J. Proximal Tibial Opening Wedge Osteotomy as the Initial Treatment for Chronic Posterolateral Corner Deficiency in the Varus Knee: A Prospective Clinical Study. The American journal of sports medicine 2007;35(11):1844-50. Crossref

4. Sabzevari S, Ebrahimpour A, Roudi MK, Kachooei AR. High tibial osteotomy: a systematic review and current concept. Archives of Bone and Joint Surgery 2016;4(3):204. https:// www.ncbi.nlm.nih.gov/pmc/articles/PMC4969364/

5. Jung W-H, Chun C-W, Lee J-H, Ha J-H, Kim J-H, Jeong J-H. Comparative study of medial opening-wedge high tibial osteotomy using 2 different implants. Arthroscopy: The Journal of Arthroscopic \& Related Surgery 2013;29(6):106371. Crossref

6. Asik M, Sen C, Kilic B, Goksan SB, Ciftci F, Taser OF. High tibial osteotomy with Puddu plate for the treatment of varus gonarthrosis. Knee Surgery, Sports Traumatology, Arthroscopy 2006;14(10):948-54. Crossref

7. Puddu G, editor High tibial osteotomy (The arthritic knee in the young athlete, SYM 15). Abstracts book of 11th ESSKA 2000 congress and 4th world congress on sports trauma, Athens, Greece; 2004.

8. Lobenhoffer P, Agneskirchner JD. Improvements in surgical technique of valgus high tibial osteotomy. Knee surgery, sports traumatology, arthroscopy 2003;11(3):132-8. Crossref

9. Aşık, M., Medial Açık Kama Osteotomisi, Tek Planda-Puddu Plağı ile, İçinde: Esenkaya I, Özenci M, Kocabey Y, Bombacı H, Köse Ô, editörler. Diz Çevresi Osteotomileri. İstanbul: İstanbul Tıp Kitabevi; 2019. p.91-97.

10. Kyung H-S, Lee B-J, Kim J-W, Yoon S-D. Biplanar open wedge high tibial osteotomy in the medial compartment osteoarthritis of the knee joint: comparison between the Aescula and TomoFix plate. Clinics in orthopedic surgery 2015;7(2):185-90. Crossref

11. Esenkaya I, Elmali N. Proximal tibia medial open-wedge osteotomy using plates with wedges: early results in 58 cases. Knee Surgery, Sports Traumatology, Arthroscopy 2006;14(10):955-61. Crossref

12. Han S-B, Bae J-H, Lee S-J, Jung T-G, Kim K-H, Kwon JH, et al. Biomechanical properties of a new anatomical locking metal block plate for opening wedge high tibial osteotomy: uniplane osteotomy. Knee Surg Relat Res 2014;26(3):15561. Crossref

13. LaPrade RF, Wentorf F. Diagnosis and treatment of posterolateral knee injuries. Clinical Orthopaedics and Related Research(1976-2007) 2002;402:110-21. Crossref

14. Fujisawa $Y$, Masuhara K, Shiomi S. The effect of high tibial osteotomy on osteoarthritis of the knee. An arthroscopic study of 54 knee joints. Orthop Clin North Am 1979;10(3):585-608.

15. Dugdale TW, Noyes FR, Styer D. Preoperative planning for high tibial osteotomy. The effect of lateral tibiofemoral separation and tibiofemoral length. Clin Orthop Relat Res 1992(274):248-64. Crossref
16. Chahla J, Dean CS, Mitchell JJ, Moatshe G, Cruz RS, LaPrade RF. Medial opening wedge proximal tibial osteotomy. Arthroscopy techniques 2016;5(4): e919-e28. Crossref

17. LaPrade RF, Barrera Oro F, Ziegler CG, Wijdicks CA, Walsh MP. Patellar height and tibial slope after opening-wedge proximal tibial osteotomy: a prospective study. The American journal of sports medicine 2010;38(1):160-70. Crossref

18. Jackman $\mathrm{T}$, LaPrade RF, Pontinen $\mathrm{T}$, Lender PA. Intraobserver and interobserver reliability of the kneeling technique of stress radiography for the evaluation of posterior knee laxity. The American journal of sports medicine 2008;36(8):1571-6. Crossref

19. Bonasia DE, Governale G, Spolaore S, Rossi R, Amendola A. High tibial osteotomy. Current reviews in musculoskeletal medicine 2014;7(4):292-301. https://www.ncbi.nlm.nih. gov/pmc/articles/PMC4596221/

20. Zaffagnini S, Bonanzinga T, Grassi A, Muccioli GMM, Musiani $\mathrm{C}$, Raggi $\mathrm{F}$, et al. Combined $\mathrm{ACL}$ reconstruction and closingwedge HTO for varus angulated ACL-deficient knees. Knee Surgery, Sports Traumatology, Arthroscopy 2013;21(4):93441. Crossref

21. Lobenhoffer P. Importance of osteotomy around to the knee for medial gonarthritis. Indications, technique and results. Der Orthopade 2014;43(5):425-31. Crossref

22. Puddu G. International symposium on operative and biologic treatments in sport medicine. Colonia 2006.

23. Polat G, Balci HI, Cakmak MF, Demirel M, Sen C, Asik M. Long-term results and comparison of the three different high tibial osteotomy and fixation techniques in medial compartment arthrosis. Journal of orthopaedic surgery and research 2017;12(1):44. Crossref

24. Chahla J, Dean CS, Mitchell JJ, Moatshe G, Serra Cruz R, LaPrade RF. Medial Opening Wedge Proximal Tibial Osteotomy. Arthrosc Tech 2016;5(4): e919-e28. Crossref

25. Cantin O, Magnussen RA, Corbi F, Servien E, Neyret P, Lustig $S$. The role of high tibial osteotomy in the treatment of knee laxity: a comprehensive review. Knee Surgery, Sports Traumatology, Arthroscopy 2015;23(10):3026-37. Crossref

26. Schröter S, Gonser CE, Konstantinidis L, Helwig P, Albrecht D. High complication rate after biplanar open wedge high tibial osteotomy stabilized with a new spacer plate (Position HTO plate) without bone substitute. Arthroscopy: The Journal of Arthroscopic \& Related Surgery 2011;27(5):64452. Crossref

27. Spahn G. Complications in high tibial (medial opening wedge) osteotomy. Archives of orthopaedic and trauma surgery 2004;124(10):649-53. Crossref

28. van den Bekerom MP, Patt TW, Kleinhout MY, van der Vis HM, Albers GR. Early Complications After High Tibial Osteotomy-A Comparison of Two Techniques. The journal of knee surgery 2008;21(01):68-74. Crossref

29. Brinkman J-M, Lobenhoffer P, Agneskirchner J, Staubli A, Wymenga A, Van Heerwaarden R. Osteotomies around the knee: patient selection, stability of fixation and bone healing in high tibial osteotomies. The Journal of bone and joint surgery British volume 2008;90(12):1548-57. Crossref

30. Martin R, Birmingham TB, Willits K, Litchfield R, LeBel M-E, Giffin JR. Adverse event rates and classifications in medial opening wedge high tibial osteotomy. The American journal of sports medicine 2014;42(5):1118-26. Crossref

31. Woodacre T, Ricketts M, Evans JT, Pavlou G, Schranz P, Hockings $M$, et al. Complications associated with opening wedge high tibial osteotomy-a review of the literature and of 15 years of experience. The Knee 2016;23(2):276-82. Crossref 
32. Osti M, Gohm A, Schlick B, Benedetto KP. Complication rate following high tibial open-wedge osteotomy with spacer plates for incipient osteoarthritis of the knee with varus malalignment. Knee Surgery, Sports Traumatology, Arthroscopy 2015;23(7):1943-8. Crossref

33. Stoffel K, Stachowiak G, Kuster M. Open wedge high tibial osteotomy: biomechanical investigation of the modified Arthrex Osteotomy Plate (Puddu Plate) and the TomoFix Plate. Clinical biomechanics 2004;19(9):944-50. Crossref

34. Zhim F, Laflamme GY, Viens H, Saidane K, Yahia LH. Biomechanical stability of high tibial opening wedge osteotomy: internal fixation versus external fixation. Clinical Biomechanics 2005;20(8):871-6. Crossref

35. Agneskirchner J, Freiling D, Hurschler C, Lobenhoffer P. Primary stability of four different implants for opening wedge high tibial osteotomy. Knee surgery, sports traumatology, arthroscopy 2006;14(3):291-300. Crossref
36. Kim KJ, Song EK, Seon JK, Seol JH. Biomechanical study of the fixation plates for opening wedge high tibial osteotomy. Knee Surg Relat Res 2015;27(3):181. Crossref

37. Aryee $\mathrm{S}$, Imhoff $A B$, Rose $T$, Tischer $T$. Do we need synthetic osteotomy augmentation materials for opening-wedge high tibial osteotomy. Biomaterials 2008;29(26):3497-502. Crossref

38. Amendola A, Bonasia DE. Results of high tibial osteotomy: review of the literature. International orthopaedics 2010;34(2):155-60. Crossref

39. El-Assal MA, Khalifa YE, Abdel-Hamid MM, Said HG, Bakr HM. Opening-wedge high tibial osteotomy without bone graft. Knee Surgery, Sports Traumatology, Arthroscopy. 2010;18(7):961-6. Crossref

40. Kaze AD, Maas S, Waldmann D, Zilian A, Dueck K, Pape D. Biomechanical properties of five different currently used implants for open-wedge high tibial osteotomy. Journal of experimental orthopaedics. 2015;2(1):14. Crossref 